\title{
Do Cardiologists at a University Hospital Adopt the Guidelines for the Treatment of Heart Failure?
}

\author{
Antonio Carlos Pereira Barretto, Moacyr Roberto Cucê Nobre, Inês Lancarotte, Airton Roberto Scipioni, \\ José Antonio Franchini Ramires \\ São Paulo, SP - Brazil
}

Objective - To verify whether the guidelines for the treatment of heart failure have been adopted at a university hospital. The guidelines recommend the following: use of angiotensin-converting enzyme inhibitors for all patients with systolic ventricular dysfunction, use of digitalis and diuretics for symptomatic patients, use of beta-blockers for patients in functional classes II or III, use of spironolactone for patients in functional classes III or IV.

Methods - We analyzed the prescriptions of $199 \mathrm{pa}$ tients. All these patients had ejection fraction $(E F) \leq 0.50$, their ages ranged from 25 to 86 years, and 142 were males. Cardiomyopathy was the most frequent diagnosis: 67 (33.6\%) patients had dilated cardiomyopathy, 65 (32.6\%) had ischemic cardiomyopathy.

Results - Angiotensin-converting enzyme inhibitors were prescribed for $93 \%$ of the patients. $71.8 \%$ also had a prescription for digitalis, $86.9 \%$ for diuretics, $27.6 \%$ for spironolactone, $12 \%$ for beta-blockers, $37.2 \%$ for acetylsalicylic acid, $6.5 \%$ for calcium channel antagonists, and $12.5 \%$ for anticoagulants. In regard to vasodilators, $71 \%$ of the patients were using captopril (85.2mg/day), $20 \%$ enalapril (21.4mg/day), 3\% hydralazine and nitrates. In $71.8 \%$ of the cases, the dosages prescribed were in accordance with those recommended in the large studies.

Conclusion-Most patients were prescribed the same doses as those recommended in the large studies. Brazilian patients tolerate well the doses recommended in the studies, and that not using these doses may be a consequence of the physician's fear of prescribing them and not of the patient's intolerance.

Key words: heart failure, angiotensin-converting enzyme inhibitor, beta-blockers, anticoagulation

Instituto do Coração do Hospital das Clínicas - FMUSP

Mailing address: Antonio Carlos Pereira Barretto - InCor - Av. Dr. Enéas C. Aguiar, 44

- 05403-000 - São Paulo, SP, Brazil - e-mail: pereira.barreto@incor.usp.br

English version by Stela Maris C. e Gandour
As a consequence of new therapeutical schedules inducing a great reduction in morbidity and mortality, the treatment of heart failure has recently been modified. The publication of studies on spironolactone and beta-blockers has led to the conclusion that these drugs should be added to the conventional treatment for heart failure with angiotensin-converting enzyme inhibitors, digitalis, and diuretics, because with this association, patients become less symptomatic, decompensate less, require less hospitalization, and have a lower mortality rate as the disease progresses ${ }^{1-4}$.

Epidemiological studies carried out in several countries, however, have shown that this management has not been adopted by most cardiologists for many reasons ${ }^{5,6}$.

As no consistent Brazilian data on this topic exist, we assessed, for 1 month, how physicians in a tertiary hospital in São Paulo were treating heart failure and how many were adopting the guidelines currently recommended.

\section{Methods}

During October '99, we reviewed and analyzed the prescriptions of 199 patients with ventricular dysfunction (ejection fraction $\leq 0.50$ ) and symptomatic heart failure classified as functional classes II, III, and IV according to the criteria of the New York Heart Association. These patients were being treated by different teams of medical specialists at the outpatient clinics of the Instituto do Coração of the HCFMUSP(InCor).

These 199 patients comprised all patients with ventricular dysfunction, who sought the ambulatory clinics of general cardiology, coronary artery diseases, geriatrics, valvar heart diseases, and heart failure at $16(40 \%)$ time periods of a total of 40 possible time periods during the month. In this study we named the services with letters (service A, B, C, D, and $\mathrm{E}$ ), which do not correspond to the above presenting order. These outpatient clinics were chosen because almost all patients with ventricular dysfunction followed up at InCor were treated at them.

The age of the patients ranged from 25 to 86 years (mean $58.4 \pm 13.8$ years), and 142 were males and 57 were females. 
Assessment performed on M-mode echocardiography revealed the following: left ventricular mean diameter of $57.9 \pm 8.5 \mathrm{~mm}$, left ventricular ejection fraction of $0.40 \pm 0.07$, and left atrial mean diameter of $44.9 \pm 8.8 \mathrm{~mm}$. In the echocardiography unit, where all echocardiographies were performed, the following values were considered normal (for adult individuals, weights ranging from 51 to $90 \mathrm{~kg}$ ): left ventricular diastolic diameters ranging from 38 to $52 \mathrm{~mm}$, left atrial diameters ranging from 28 to $40 \mathrm{~mm}$, ejection fraction (assessed through the cube method) from 0.58 to 0.80 .

The major cause of ventricular dysfunction was dilated cardiomyopathy in $67(33.6 \%)$ patients and ischemic heart disease in 65 (32.6\%) patients. Ventricular dysfunction was associated with Chagas' disease in $21(10.5 \%)$ patients and with hypertension in $23(11.5 \%)$ patients. It was secondary to valvar heart disease in $20(9.5 \%)$ patients and to alcoholic cardiomyopathy in $3(1.5 \%)$ patients.

All 199 patients were under treatment in different units at the hospital as follows: 90 (45.2\%) patients were being followed up in the general cardiology outpatient clinics, 44 (22.1\%) patients in the chronic coronary artery disease outpatient clinics, $28(14.0 \%)$ patients in the geriatrics outpatient clinics, 25 (12.5\%) patients in the heart failure unit, and $12(6.0 \%)$ in the valvar heart disease outpatient clinics. Table I shows some characteristics of the population studied according to the major cause of heart disease.

We analyzed the medications prescribed for these patients and their dosages, and we checked the percentage of prescriptions in which the dosages recommended by the guidelines ${ }^{7}$ were prescribed.

We considered a recommended dosage of the angiotensin-converting enzyme inhibitors to be minimum values of $75 \mathrm{mg}$ of captopril, or $20 \mathrm{mg}$ of enalapril, or $20 \mathrm{mg}$ of lisinopril (standardized drugs at the hospital), 25mg of carvedilol twice a day, and $25 \mathrm{mg}$ of spironolactone. We also analyzed the following: the prevalence of atrial fibrillation, the frequency of prescription of aspirin and oral anticoagulation agents, the type of prescription according to the major diagnosis, the degree of ventricular dysfunction, and the team of medical specialists taking care of the patient.

\section{Results}

In the population studied, the patients with alcoholic cardiomyopathy were younger than those with other cardiomyopathies, and the patients with Chagas' disease were younger than those with dilated, hypertensive, and ischemic cardiomyopathy. The remaining patients had similar ages.

We analyzed whether ventricular impairment was similar in the different heart diseases, and no significant differences were found in ventricular impairment assessed through ejection fraction. A trend toward higher ejection fraction was found in patients with hypertensive cardiomyopathy than in those with Chagas' cardiomyopathy $(\mathrm{p}=0.088)$, in those with dilated cardiomyopathy $(0.055)$, and in those with ischemic cardiomyopathy $(\mathrm{p}=0.09)$.

We also assessed whether the degree of ventricular dysfunction was similar among patients of the different teams of medical specialties of InCor, and we found that the ejection fraction was lower in patients in service $A$ than in all patients in other services. The ejection fractions were as follows: $0.36 \pm 0.06$ in service $A$ and $0.40 \pm 0.06$ in service $B$ $(\mathrm{p}=0.008), 0.40 \pm 0.08$ in service $\mathrm{C}(\mathrm{p}=0.042), 0.42 \pm 0.08$ in service $\mathrm{D}(\mathrm{p}=0.0004)$, and $0.42 \pm 0.06$ in service $\mathrm{E}(\mathrm{p}=0.012)$. Ventricular function was also different between services $B$ and $\mathrm{D}(\mathrm{p}=0.04)$ and similar for the remaining services.

Thirty-two (16.08\%) patients had atrial fibrillation, which was more common in patients with valvar heart diseases.

All patients were on some type of medication. Only 5 $(2.5 \%)$ patients were not receiving vasodilating drugs. Prescriptions were as follows: 185 (93\%) patients were prescribed angiotensin-converting enzyme inhibitors, 6 (3.0\%) patients were prescribed hydralazine associated with isosorbide dinitrate, and $3(1.5 \%)$ patients were prescribed angiotensin II receptor antagonists. In regard to diuretics, 173 $(86.9 \%)$ patients were prescribed these drugs as follows: $121(60.80 \%)$ were prescribed furosemide, $92(46.2 \%)$ thiazide diuretics, and $40(20.1 \%)$ both drugs. Amiloride was used in $15(7.5 \%)$ patients, and digoxin in $143(71.8 \%)$ patients (fig. 1).

The patients were also prescribed the following medications: spironolactone $55(27.6 \%)$ patients, beta-blockers $24(12.0 \%)$ patients, acetylsalicylic acid $74(37.1 \%)$ patients, calcium channel antagonists $13(6.5 \%)$ patients, anticoagulants $25(12.5 \%)$ patients, potassium $12(6.0 \%)$ patients, and amiodarone 18 (9.0\%) patients.

In regard to angiotensin-converting enzyme inhibi-

\begin{tabular}{|c|c|c|c|c|c|c|c|c|}
\hline & & & & $\mathrm{ECHO}$ & & & & $\begin{array}{l}\text { Relative } \\
\text { prevalence of } \mathrm{AF}\end{array}$ \\
\hline Heart disease & $\mathrm{N}$ & Age & Males & LV & $\mathrm{EF}$ & LA & $\mathrm{AF}$ & \\
\hline Alcoholic & 3 & $47.3 \pm 9.0$ & 3 & $69.3 \pm 6.0$ & $0.40 \pm 0.05$ & $49.6 \pm 15.3$ & - & $0.0 \%$ \\
\hline Chagas' disease & 21 & $51.5 \pm 14.3$ & 12 & $69.0 \pm 8.0$ & $0.36 \pm 0.06$ & $46.5 \pm 6.4$ & 3 & $(14.2 \%)$ \\
\hline Dilated & 67 & $57.9 \pm 15.1$ & 45 & $70.4 \pm 9.9$ & $0.38 \pm 0.06$ & $46.2 \pm 9.5$ & 20 & $(29.8 \%)$ \\
\hline Hypertensive & 23 & $59.8 \pm 13.3$ & 16 & $64.5 \pm 8.7$ & $0.42 \pm 0.08$ & $42.6 \pm 8.7$ & 1 & $(4.3 \%)$ \\
\hline Ischemic & 65 & $61.4 \pm 10.9$ & 49 & $64.9 \pm 5.8$ & $0.42 \pm 0.07$ & $42.4 \pm 7.1$ & 4 & $(6.1 \%)$ \\
\hline Valvar heart disease & 20 & $57.5 \pm 16.0$ & 16 & $72.0 \pm 8.1$ & $0.41 \pm 0.07$ & $48.50 \pm 10.8$ & 8 & $(40 \%)$ \\
\hline
\end{tabular}




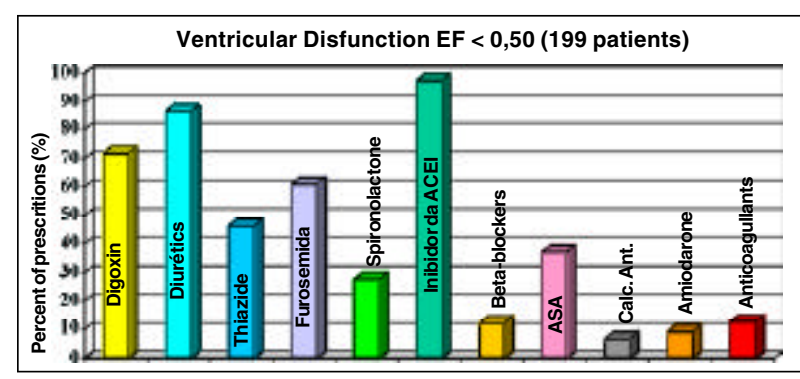

Fig. 1 - Bar graph showing the percentage of patients receiving different types of medication (92.5\% received angiotensin-converting enzyme inhibitors). Digdigitalis; Thiaz- thiazide; Fur- furosemide; Spir- spironolactone; ACEI angiotensin-converting enzyme inhibitor; Carv- carvedilol; ASA - acetylsalicylic acid; Calc. Ant. - calcium channel antagonist; Am- amiodarone; Anticoag. anticoagulants.

tors, $142(71.3 \%)$ patients were prescribed captopril in a mean dosage of $85.2 \mathrm{mg} / \mathrm{day}$, of whom $102(71.2 \%)$ were prescribed dosages considered appropriate (above $75 \mathrm{mg}$ /day). Thirty-nine (19.5\%) patients were prescribed enalapril in a mean dosage of $21.4 \mathrm{mg} /$ day, 29 (74.3\%) of whom were receiving appropriate dosages (above 20mg/day). Lisinopril was prescribed for 3 (1.5\%) patients; all received appropriate dosages.

Thiazide diuretics were prescribed in dosages ranging from $12.5 \mathrm{mg}$ to $50 \mathrm{mg} / \mathrm{day}$ (mean dosage $42.7 \mathrm{mg} / \mathrm{day}$ ). Furosemide was prescribed in dosages ranging from 20 to $240 \mathrm{mg} /$ day (mean dosage $40.3 \mathrm{mg} /$ day).

Spironolactone was used in dosages ranging from 25 to $200 \mathrm{mg}$, and 43 (78.18\%) out of the 55 patients on spironolactone used 25 or $50 \mathrm{mg} /$ day. The mean dosage was $62.72 \mathrm{mg} /$ day.

Carvedilol was prescribed for $19(9.54 \%)$ patients in dosages ranging from $3.125 \mathrm{mg}$ once a day to $12.5 \mathrm{mg}$ twice a day (mean dosage of $6.5 \mathrm{mg} /$ day); 5 patients were prescribed other beta-blockers (propranolol 4 patients and atenolol 1 patient).

Calcium channel antagonists were prescribed for 13 patients as follows: diltiazem for 6 patients, amlodipine for 5 , nitrendipine for 1 patient, and nifedipine for 1 patient.

Aspirin was prescribed for 64 patients in dosages ranging from 100 to $300 \mathrm{mg} /$ day (mean dosage $125 \mathrm{mg} /$ day).

Anticoagulation with dicumarol was being performed in 25 (12.5\%) patients, and 17 patients had atrial fibrillation; 13 werenot receiving antithrombotic or anticoagulant medication, 10 were receiving aspirin, and 17 were receiving anticoagulation.
Table II shows how frequently drugs are prescribed according to the major diagnosis of heart disease. We note that, in general, prescriptions were similar for different heart diseases, except for digoxin, which was less prescribed, and aspirin and calcium channel antagonists, which were mostly prescribed for patients with ischemic heart disease.

\section{Discussion}

Pharmacological management of patients with heart failure has undergone changes due to diffusion of the recent results of the large studies. Since the publication of the RALES, US-Carvedilol CIBIS II, and MERIT-HF studies, patients with heart failure should have been receiving, in addition to angiotensin-converting enzyme inhibitors, digitalis and diuretics, spironolactone, and beta-blockers ${ }^{1-4}$. Even though these studies have shown in an unquestionable manner that these drugs improve the evolution of patients with heart failure, they have not been prescribed for most patients.

The lower frequency of prescribing these drugs may result from several factors, among which we may cite the delay in adopting this management by cardiologists, who, without the required experience, slowly adopt new management techniques and, sometimes, adopt them without knowing how to prescribe the correct doses, prescribing lower doses than those recommended and established as effective.

In several developed countries, the analysis of medical prescriptions has shown that most physicians do not adopt the guidelines integrally ${ }^{5,6}$. In Brazil, we do not have reliable data on how our patients with heart failure are managed. From informal chats with doctors during medical congresses and meetings, we conclude that recommendations are obeyed but with adaptations.

In an attempt to evaluate these data more scientifically, we carried out this study in a large referral hospital in São Paulo, where we assessed the management of patients with left ventricular dysfunction and heart failure by doctors of the different services in the hospital.

The inclusion criteria of the study were the following: presence of systolic ventricular dysfunction characterized by a reduction in left ventricular ejection fraction analyzed with the aid of echocardiography (value $\leq 0.50$ ) and heart failure classified according to the NYHA functional classes from II to IV. In subsequent days, we identified the patients

\begin{tabular}{|c|c|c|c|c|c|c|c|c|c|c|c|}
\hline \multicolumn{12}{|c|}{ Table II - Treatment according to the cause of heart disease } \\
\hline Heart disease & $\mathrm{N}$ & Digitalis & Furosemide & Thiazide & Spironolactone & Potassium & Beta-blocker & ACEI & ASA & Calcium ant. & Anticoagulants \\
\hline Alcoholic & 3 & 3 & 2 & 2 & 1 & - & - & 3 & - & - & - \\
\hline Chagas' disease & 21 & 17 & 14 & 12 & 8 & 2 & 2 & 21 & 4 & - & 3 \\
\hline Dilated & 67 & 56 & 43 & 33 & 24 & 6 & 10 & 65 & 14 & 2 & 13 \\
\hline Hypertensive & 23 & 13 & 13 & 13 & 4 & 1 & 2 & 21 & 5 & 4 & 1 \\
\hline Ischemic disease & 65 & 38 & 35 & 24 & 14 & 2 & 10 & 58 & 45 & 7 & 2 \\
\hline Valvar disease & 20 & 16 & 14 & 8 & 4 & 1 & - & 17 & 6 & - & 6 \\
\hline
\end{tabular}


with ventricular dysfunction in the outpatient clinics of the hospital, and we analyzed their therapeutical prescriptions. We discarded the cases of first and second medical visits, in an attempt to avoid including initial or experimental therapeutics. We could see that most patients received, as expected, the classical scheme, which comprised digitalis, diuretics, and angiotensin-converting enzyme inhibitors ${ }^{7-13}$.

The cause of ventricular dysfunction and its severity seemed to influence the prescription of these drugs. Therefore, digitalis is less frequently prescribed for patients with ischemic heart disease, and the angiotensin-converting enzyme inhibitors more frequently prescribed for patients with hypertensive or dilated cardiomyopathies or cardiomyopathy due to Chagas' disease. This is in accordance with the evidence that digitalis may not be beneficial for patients with ischemic heart disease, and the angiotensin-converting enzyme inhibitors modify the natural history of these heart diseases, in which ventricular dysfunction is the major process ${ }^{14}$.

In the quantitative analysis of the treatment, we observed that $97.5 \%$ of the patients were using vasodilators as follows: angiotensin-converting enzyme inhibitors in $93 \%$ of the patients, hydralazine and nitrate in $3 \%$, and angiotensin II antagonist in $1.5 \%$. Only 5 (2.5\%) patients were not prescribed vasodilators, $71 \%$ had a prescription for captopril, $20 \%$ for enalapril, $3 \%$ for hydralazine and nitrates, $1.5 \%$ for lisinopril, and $1.5 \%$ for losartan. The mean dosage of captopril prescribed was $85.2 \mathrm{mg} /$ day and of enalapril was $21.4 \mathrm{mg} /$ day. Considering these dosages, $71.8 \%$ of the patients were prescribed the dosages recommended in the large studies $(75 \mathrm{mg} /$ day of captopril and $20 \mathrm{mg} /$ day of enalapril) ${ }^{8-13}$. No patient had a prescription for a dosage below $25 \mathrm{mg} /$ day of captopril or $5 \mathrm{mg} /$ day of enalapril. Of the patients with an ejection fraction below 0.35 and those with an ejection fraction above $0.36,74 \%$ and $66 \%$, respectively, received the dosages recommended (fig. 2). The 5 patients

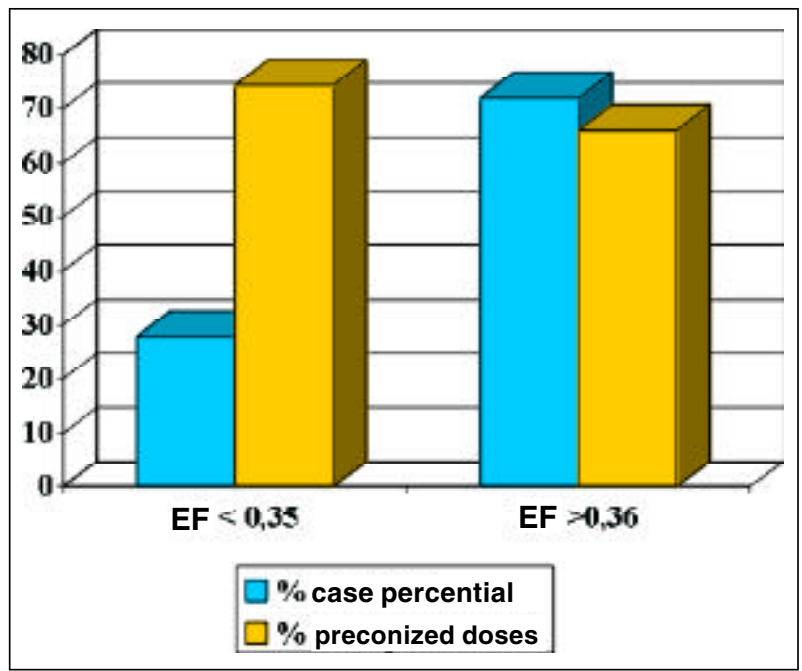

Fig. 2 - Seventy-two percent of the patients had an ejection fraction $>0.36$. Of those patients with an ejection fraction $<0.35$, a higher percentage of patients was prescribed doses of angiotensin-converting enzyme inhibitors recommended in the large studies. with no prescription for vasodilators had either ventricular dysfunction secondary to coronary artery disease ( 4 cases) or to valvar heart disease (1 case), situations in which the physician is much more concerned with the underlying disease than with the ventricular dysfunction itself. In 3 of these patients, ventricular function was 0.50 , a situation in which indication for the use of angiotensin-converting enzyme inhibitors was not evidence-based.

These results allow some inferences. Prescribing angiotensin II receptor antagonists for patients who do not tolerate angiotensin-converting enzyme inhibitors due to cough is routine management among physicians. As only $1.5 \%$ of the patients had been prescribed angiotensin receptor antagonists, one may conclude that limiting cough is a much rarer fact than usually considered. Similar results were found in the SPICE Study ${ }^{15}$. This study, which was carried out in a population being treated for heart failure, in which intolerance for angiotensin-converting enzyme inhibitors was being sought, has identified $3.6 \%$ of patients with cou$\mathrm{gh}$, which is a low incidence of this side effect in patients with heart failure.

The same was found in regard to renal failure, which would be induced or worsened by angiotensin-converting enzyme inhibitors. In this situation, in our service, we replace the angiotensin-converting enzyme inhibitor by hydralazine and nitrate, and our results show that only $1.5 \%$ of our patients were receiving these medications. In the SPICE Study ${ }^{15}$, renal failure was detected in $2.2 \%$ of the cases, which is a figure very similar to that found in our study. Data suggest that renal failure worsened by the use of angiotensin-converting enzyme inhibitors is so important that treatment with this drug should be stopped, but this is not a frequent finding in patients with heart failure on an ambulatory treatment basis.

These data show that, in general, physicians at InCor have adopted the guidelines in regard to the doses of angiotensin-converting enzyme inhibitors. Significant information deriving from the doses used is that most patients tolerate total doses of the drugs, and that in our institution, even the low doses are higher than those used by most cardiologists in their private practice. Another interesting finding that had already been observed in a previous analysis in $1997^{8}$ is that patients with greater ventricular impairment were receiving higher doses of inhibitors than those with a lower impairment. This is a noteworthy finding because, even though these more critically ill patients were expected not to tolerate the recommended doses, we observed exactly the opposite. Due to the fact that these are more critically ill patients, the physicians try harder to optimize their treatment, increasing the percentage of cases using the recommended doses. Tolerance of patients to these drugs is noteworthy.

Our results lead us to conclude that no reason exists for not increasing doses based on the possibility that patients would not tolerate higher doses. Considering that patients in our hospital tend to be more severely ill and that most of them tolerate high doses, and knowing that even the 
low doses were higher than those usually prescribed, the non-increasing might have been due to the physician's fear of increasing the dose than to dose intolerance.

We checked whether this management had been uniform among the several services at InCor, and we observed that it was not. In general, all services at InCor have prescribed angiotensin-converting enzyme inhibitors for patients with ventricular dysfunction, with increasing doses in the last 2 years. In 1997, in a similar study ${ }^{16}$, we found that the mean dose of captopril was $71.9 \mathrm{mg}$, and in 1999 it was $85.29 \mathrm{mg}$. We also found an increase in the frequency of prescription of these drugs from $87 \%$ to $97.5 \%$ (fig. 3). However, we observed that in certain services, the patients were not receiving the doses recommended in the large studies (fig. 4).

Other prescriptions included the following drugs: digitalis in $71.8 \%$ of the patients, diuretics in $86.9 \%$, spironolactone in $27.6 \%$, beta-blockers in $12.0 \%$, acetylsalicylic acid in $37.2 \%$, calcium channel antagonists in $6.5 \%$, and anticoagulant drugs in $12.5 \%$ (fig. 1).

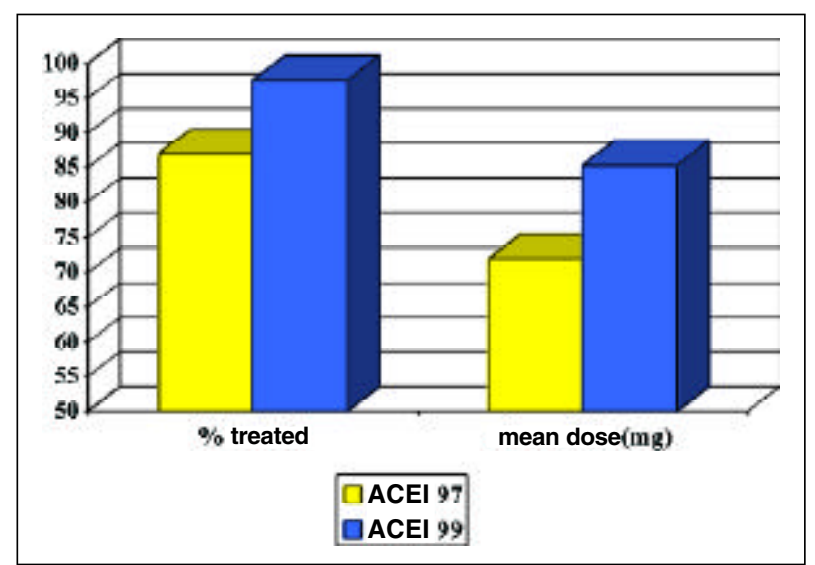

Fig. 3 - The percentage of patients treated with angiotensin-converting enzyme inhibitors or other vasodilators and of those receiving the doses recommended in the large studies increased from 1997 to 1999.

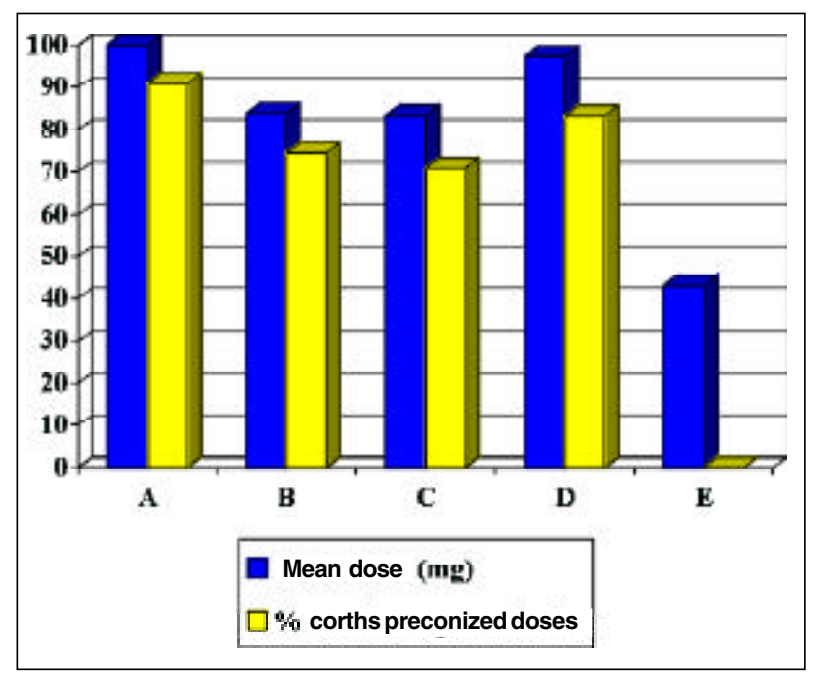

Fig. 4 - The percentage of patients who were prescribed angiotensin-converting enzyme inhibitors and total doses varied according to the service in which the patient was registered.
According to the results of the RALES Study ${ }^{1}$, patients with functional class III or IV heart failure should receive spironolactone; we observed that at InCor outpatient clinics, $27.6 \%$ of the patients had received it. In other services at InCor, the following percentages of patients had received spironolactone: $52 \%$ of the patients in service $\mathrm{A}$, $33.3 \%$ in service B, $28.5 \%$ in service C, $9.0 \%$ in service D, and no patient in service $\mathrm{E}$ (fig. 5). In regard to the doses, they were as follows: $25 \mathrm{mg}$ for 25 patients, $50 \mathrm{mg}$ for 18 patients, $100 \mathrm{mg}$ for 11 patients, and $200 \mathrm{mg}$ for 1 patient. Considering that the RALES Study recommend doses ranging from 25 to $50 \mathrm{mg}$, it would be interesting to check why higher doses were being used.

Based on the results of the US-Carvedilol Study ${ }^{2}$ in 1998 and the CIBIS-II ${ }^{3}$ and MERIT-HF ${ }^{4}$ studies in 1999 , beta-blockers should be prescribed for patients with ventricular dysfunction in functional class II or III. We observed that only $24(12.06 \%)$ patients had been prescribed carvedilol at the mean dosage of $6.57 \mathrm{mg}$ twice a day. Four other patients had been prescribed propranolol and another patient atenolol, for controlling hypertension or coronary artery disease.

In the outpatient clinic of service A, $44 \%$ of the patients had been prescribed carvedilol, in service C $14.2 \%$, in service D $4.5 \%$, in service B $2.2 \%$, and in service E no patient. No prescription for $25 \mathrm{mg}$ twice a day was observed.

Calcium channel antagonists had been prescribed for 13 patients, particularly for the hypertensive ones and those with coronary artery disease. We observed that 6 patients had a prescription for diltiazem, 1 patient for nitrendipine, and 1 patient for nifedipine. Only 5 patients had been prescribed amlodipine, which, of the calcium channel antagonists, seems to interfere less with the cardiac function, according to the PRAISE Study ${ }^{17}$.

The results of the PRAISE I and II and V-HeFT-3 studies ${ }^{17,18}$ recommend amlodipine or felodipine (third generation antagonists) for ventricular dysfunction requiring calcium channel antagonists, because they do not increase the manifestations of heart failure. On the other hand, diltiazem and nifedipine should be suspended because they are known to increase these manifestations.

The graph in figure 6 shows the frequency of prescription compared with data observed in the SPICE ${ }^{15}$ and SOLVD ${ }^{8,9}$ studies, where differences are observed mainly in regard to beta-blockers. In our study, the frequency of

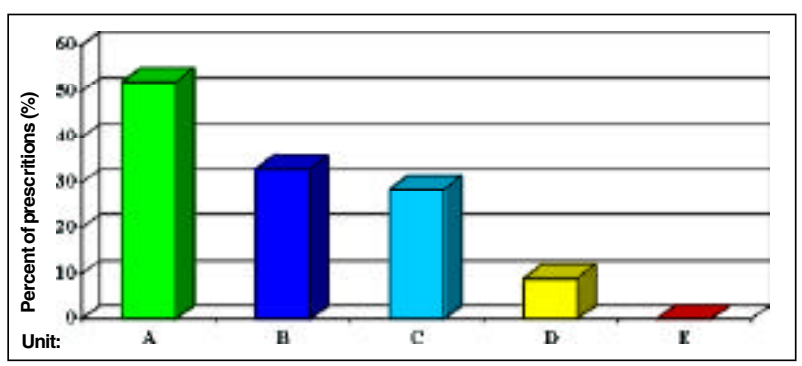

Fig. 5 - Percentage of patients who were prescribed spironolactone in the different services studied. 


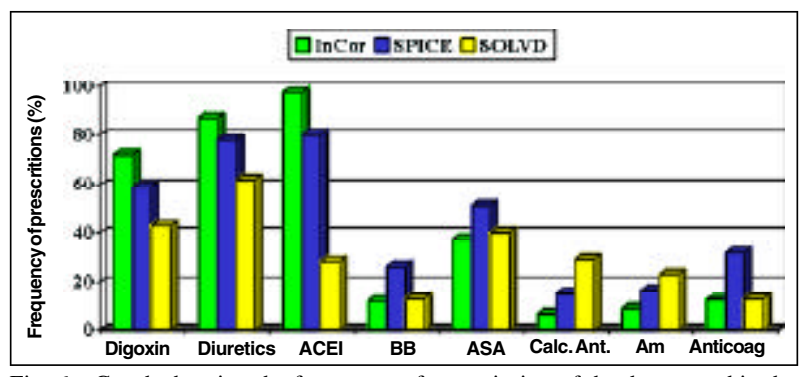

Fig. 6 - Graph showing the frequency of prescription of the drugs used in the treatment of heart failure in our study and in the SOLVD and SPICE studies.

ACEI - angiotensin-converting enzyme inhibitor, BB- beta-blockers, ASA acetylsalicylic acid, Calc. ant. - calcium channel antagonists, Amiod - amiodarone, Anticoag- anticoagulants.

prescription was lower than that observed in the SPICE Study, but similar to that of the SOLVD Study in 1992. This result may be due to the fear of many cardiologists of prescribing beta-blockers to their patients. The same happens with anticoagulants and antiplatelet drugs, which were more frequently prescribed in the 2 international studies. On the other hand, we used less calcium channel antagonists, because in our case series we had a predominance of dilated cardiomyopathy, as apposed to the 2 international studies in which ischemic cardiomyopathy predominated.

Another controversial point is the management of patients with atrial fibrillation, which significantly increases the incidence of thromboembolic phenomena. Anticoagulation could be the best way to prevent embolism, but aspirin or another antiplatelet agent could be used in patients with contraindication to anticoagulants ${ }^{19-21}$.

Atrial fibrillation was observed in 40 patients, 17 of whom were receiving anticoagulation therapy, 10 were using aspirin, and 13 used no medication. Was this management correct?

These numbers show that we have not yet totally adopted the correct management of anticoagulation in patients with atrial fibrillation.

Another point that deserves consideration is the prescription of aspirin for patients using angiotensin-converting enzyme inhibitors, because aspirin could reduce their effect due to its action on bradykinin ${ }^{22-24}$.

We observed that 64 patients were using aspirin, 49 of them were using $100 \mathrm{mg}, 14$ patients $200 \mathrm{mg}$, and 1 patient $300 \mathrm{mg}$. Considering the diagnosis of heart disease, we observed that aspirin was prescribed for $69.2 \%$ of the patients with ischemic cardiomyopathy, for $21.7 \%$ of the hypertensive patients, for $30 \%$ of the patients with valvar heart disease, for $20.8 \%$ of the patients with dilated cardiomyopathy, and for $19.0 \%$ of the patients with Chagas' disease. Some articles ${ }^{22-24}$ and a thesis of our institution have shown that aspirin may reduce or block the vasodilating effect of angiotensinconverting enzyme inhibitors, particularly at doses of 200 or
$300 \mathrm{mg}$. In our outpatient clinic and in the daily clinical practice, this association is common. Should we change the antiplatelet agent in patients with heart failure?

This characteristic of aspirin use is controversial and has been discussed and analyzed in the literature. In patients with coronary artery disease, in whom the benefits of aspirin use has been well established, it is suggested that aspirin prescription should be maintained, even though some researchers suggest that aspirin may be replaced by other antiaggregating agents that do not interfere with the action of angiotensin-converting enzyme inhibitors. In patients with heart failure due to other causes, aspirin should be avoided because its beneficial effect on preventing embolic phenomena has not been shown, and, in addition, evidence exists, as in the WASH Study, that aspirin use increases events such as hospitalization and death.

Finally, we tried to assess whether the degree of ventricular impairment could explain the difference in management observed among the different services, because service A seems to be the most obedient in regard to the guidelines, prescribing high doses of angiotensin-converting enzyme inhibitors, spironolactone, and beta-blockers for the patients. Service E does not seem to abide by these rules, because no patient received high doses of angiotensin-converting enzyme inhibitors, spironolactone, and beta-blockers. The management of the remaining services lies between these 2 extremes. Even though service A handles more critically ill patients, patients in the other services are similar in regard to severity of disease. Therefore, we may not accept that differences in management are only due to the severity of cardiac impairment.

In regard to the question "Should patients with heart failure be treated by a specialized team?", our data allow answering that they should, because service A is the Heart Failure Unit, and the results have shown that a most significant percentage of patients are treated there with medications and doses recommended by the guidelines ${ }^{25,26}$. This fact was not observed with the same frequency in the other teams.

In conclusion, the guideline for prescribing angiotensinconverting enzyme inhibitors for patients with ventricular dysfunction is adopted by cardiologists, because only $2.5 \%$ of the patients did not receive this type of medication. Even though more recent, the prescription of spironolactone is already more frequently adopted than that of beta-blockers. Despite their noxious effects, calcium channel antagonists were prescribed in $6.5 \%$ of the patients. Aspirin, which may reduce the effects of angiotensin-converting enzyme inhibitors, was prescribed in $37.2 \%$ of the patients. Differences in management among the diverse services of InCor allow the assumption that more specialized teams in the treatment of heart failure adopt, in a more complete manner, the guidelines for the treatment of this disease. 


\section{References}

1. Pitt B, Zannad F, Remme WJ, et al. The effect of spironolactone on morbidity and mortality in patients with severe heart failure. N Engl J Med 1999; 341: 709-17.

2. Packer M, Bristow MR, Cohn JN, et al. Effect of carvedilol on morbidity and mortality in chronic heart failure. N Engl J Med 1996; 334: 1349-55.

3. CIBIS-II investigators and committees. The cardiac insufficiency bisoprolol study II (CIBIS-II). Lancet 1999; 353: 9-13.

4. Merit-HF Study group. Effect of metoprolol CR/XL in chronic heart failure: Metoprolol CR/XL randomized intervention trial in congestive heart failure (MERIT-HF). Lancet 1999; 353: 2001-7.

5. Edep ME, Shah NB, Tateo IM, Massie BM. Differences between primary care physicians and cardiologists in management of congestive heart failure: Relation to practice guidelines. J Am Coll Cardiol 1997; 30: 518-26.

6. Greenfield S, Nelson EC, Zubkoff M, et al. Variations in resource utilization among medical specialties and systems care: results from the Medical Outcomes Study. JAMA 1992; 153: 2229-37.

7. II Diretrizes da Sociedade Brasileira de Cardiologia para o Diagnóstico e Tratamento da Insuficiência Cardíaca. Arq Bras Cardiol 1999; 72(supl. I): 1-30.

8. The SOLVD Investigators. Effect of enalapril on mortality and the development of heart failure in asymptomatic patients with reduced left ventricular ejection fraction. N Engl J Med 1992: 327: 685-91.

9. The SOLVD Investigators. Effect of enalapril on survival in patients with reduced left ventricular ejection fraction and congestive hear failure. N Engl J Med 1991; 325: 293-302.

10. Packer M, Poole-Wilson A, Armstrong PW, et al. Comparative effect of low and high doses of the angiotensin-converting enzyme inhibitor, lisinopril, on morbidity and mortality in chronic heart failure (ATLAS study). Circulation 1999; 100: 2312-8.

11. The CONSENSUS trial study group. Effects of enalapril on mortality in severe congestive heart failure: results of the Cooperative North Scandinavian Enalapril Survival Study (CONSENSUS). N Engl J Med 1987; 316: 1429-35.

12. Pfeffer MA, Braunwald E, Moye LA, et al. Effect of captopril on mortality and morbidity in patients with left ventricular dysfunction after myocardial infarction. Results on the survival and ventricular enlargement trial (SAVE). N Engl J Med 1992; 327: 669-77.

13- The Acute Infarction Ramipril Efficacy (AIRE) Study Investigators. Effect of ramipril on mortality and morbidity of survivors of acute myocardial infarction with clinical evidence of heart failure. Lancet 1993; 342: 821-8.
14. The Digitalis Investigation Group. The effect of digoxin on mortality and morbidity in patients with heart failure. N Engl J Med 1997; 336: 525-33.

15. Bart BA, Ertl G, Held P, et al. Contemporary management of patients with left ventricular systolic dysfunction. Results from the Study of patients intolerance of Converting Enzyme Inhibitors (SPICE) registry. Eur Heart J 1999; 20: 1182-90.

16. Barretto ACP, Wajngarten M, Serro-Azul JB, et al. Tratamento medicamentoso da insuficiência cardíaca em hospital terciário de São Paulo. Arq Bras Cardiol 1997; 69: 375-9.

17. Packer M, O'Connor CM, Ghali JK, et al. The effect of amlodipine on morbidity and mortality in severe chronic heart failure. N Engl J Med: 1996; 335: 1107-14.

18- Cohn JN, Ziesche S, Smith R, et al. Effect of the calcium antagonist felodipine as supplementary therapy in patients with chronic heart failure treated with enalapril (V-HeFt III). Circulation 1997; 96: 856-63.

19. The Stroke Prevention in atrial fibrillation investigators. Predictors of thromboembolism in atrial fibrillation: I. Clinical features of patients at risk. Ann Intern Med 1992; 116: 1-5.

20. Hart RG, Benavente O, McBride R, Pearce LA. Antithrombotic therapy to prevent stroke in patients with atrial fibrillation: A meta-analysis. Ann Intern Med 1999; 131: 492-501.

21. Golzari H, Cebul RD, Bahler RC. Atrial fibrillation: Restoration and maintenance of sinus rhythm and indications for anticoagulation therapy. Ann Intern Med 1996; 125: 311-23.

22. Viecilli PN, Park M, Santos SR, et al. Antagonism of captopril by aspirin in severe heart failure: Hemodynamic and Neurohormonal demonstration. Circulation 1999; 100(suppl): I-536.

23. Spaulding C, Charbonnier B, Cohen-Solal A, et al. Acute hemodynamic interaction of aspirin and ticlopidina with enalapril. Results of a double-blind, randomized comparative trial. Circulation 1998; 98: 757-65.

24. Hall D, Zeitler H, Rudolph W. Counteraction of the vasodilatatory effects of enalapril by aspirin in severe heart failure. J Am Coll Cardiol 1992; 20: 1549-55.

2.- Hanumanthu S, Butler J, Chomsky D, et al. Effect of a heart failure program on hospitalization frequency and exercise tolerance. Circulation 1999; 96: 2842-8.

26. Fonarow GC, Stevenson LW, Walden JA, et al. Impact of a comprehensive management program on hospital readmission and functional status of patients with advanced heart failure. J Am Coll Cardiol 1997; 30: 725-32. 